\title{
The Control of Pollutant Emission from Syngas Flames Using the Oxidizer Dilution Approach
}

\author{
Masoud Darbandi $^{1}$, Majid Ghafourizadeh ${ }^{1}$, Gerry E. Schneider ${ }^{2}$ \\ ${ }^{1}$ Department of Aerospace Engineering, Centre of Excellence in Aerospace Systems, Sharif University of Technology \\ P. O. Box 11365-8639, Tehran, Iran \\ darbandi@sharif.edu; majid.ghafourizadeh@gmail.com \\ ${ }^{2}$ Department of Mechanical and Mechatronics Engineering, University of Waterloo \\ Waterloo, Ontario, N2L 3G1, Canada \\ gerry.schneider@uwaterloo.ca
}

\begin{abstract}
In this work, we aim to control the emission of greenhouse gases from different syngas-fuel-based flames or the bluff-body stabilized turbulent flame. First, we validate our numerical analysis by solving a benchmark test case using the detailed-chemistry and compare our obtained results with those of experiment. The benchmark test case is fed with a syngas fuel. The comparison shows that our numerical analysis can predict the structure of benchmark flame very well. Second, we simulate the test case with fuelling the same flame; however, fed with different syngas fuels. Then, we compare their achieved greenhouse gas emissions with each other. We feed the flame with different syngas fuels produced from biomass, wood waste, and turkey feathers. Considering these different syngas fuels, we extend the scope of this study and simulate these flames under different conditions of oxidizer dilution. In other words, we dilute the oxidizer by feeding extra nitrogen and report the greenhouse gases emitted from these flames. The comparison is performed to demonstrate the effect of extra nitrogen dilution on their pollution emissions. Our findings show that the dilution of oxidizer (by feeding extra nitrogen) will considerably affect the pollutants emission form these flames. The current study also shows that the emission of carbon monoxide $\mathrm{CO}$ would be seriously reduced using the extra nitrogen dilution technique.
\end{abstract}

Keywords: Syngas fuel, Air pollution, Emission Control, Oxidizer dilution, $\mathrm{CO}$ and $\mathrm{CO}_{2}$ concentrations, Turbulent flame

\section{Nomenclature}

$\begin{array}{lll}B_{z} & = & \text { buoyant force } \\ f & = & \text { mixture fraction } \\ f^{\prime 2} & = & \text { mixture fraction variance } \\ h & = & \text { total enthalpy } \\ n & = & \text { total number of species } \\ p & = & \text { pressure } \\ r, z & = & \text { radial and axial components in Cylindrical coordinates, respectively } \\ R & = & \text { gas constant } \\ T & = & \text { temperature } \\ u & = & \text { radial velocity component } \\ v & = & \text { axial velocity component } \\ \mathbf{V} & = & \text { velocity vector } \\ W & = & \text { molecular weight } \\ Y & = & \text { mass fraction } \\ \varepsilon & = & \text { turbulence dissipation rate } \\ \kappa & = & \text { turbulence kinetic energy } \\ \mu & = & \text { molecular viscosity coefficient } \\ \rho & = & \text { mixture density } \\ \chi & = & \text { scalar dissipation rate }\end{array}$

\section{Subscripts, Superscripts, and Accents}


$e \quad=\quad$ effective magnitude

$l=$ laminar

$m=$ chemical species index counter

$t=$ turbulent

\section{Introduction}

Synthesis gas (syngas), which can be obtained from natural gas, coal, petroleum, biomass, and different organic waste, has the potential to be used as a source of fuel for energy production due to its numerous advantages, i.e. lower costs, clean combustion, and pollutants reduction [1-4]. The syngas, produced through different gasification processes, is a mixture of $\mathrm{CO}$ and $\mathrm{H}_{2}$ that also contains $\mathrm{CH}_{4}, \mathrm{CO}_{2}, \mathrm{H}_{2} \mathrm{O}$, and $\mathrm{N}_{2}$. Its chemical composition is different from one to another based on its source and processing technique, i.e. the feedstock and gasifier types, the method of feedstock delivery, and the operating conditions of the gasification process.

Literature shows that the emission characteristics of syngas combustion have not been studied from different aspects. The researchers have mostly studied the combustion characteristics of syngas premixed flames since its invention [5-10]. Indeed, there is a lack of research and resources for syngas non-premixed flames. For example, the structure and fundamental combustion characteristics of the turbulent syngas non-premixed flames are not still fully-understood. The oxidizer dilution via an inert gas such as $\mathrm{N}_{2}$ is another gap in the field which its effects on the combustion and pollution characteristics of such flames should be investigated more carefully.

In present study, we first simulate a syngas turbulent non-premixed flame stabilized on an axisymmetric bluff body. We simulate this benchmark problem to examine our numerical results comparing with the data reported in the experiment. To do this, we utilize the detailed chemistry model considering 463 reversible chemical reactions between 70 chemical species. The combustion and turbulence phenomena are modelled using the steady laminar flamelet and the standard $\kappa-\varepsilon$ turbulence models, respectively. The presumed-shape probability density functions PDFs are utilized for the turbulencechemistry interaction. The round jet corrections are applied to the turbulence model and the wall function approaches are used to model the flow behaviour near the solid walls. The radiation heat transfer of different chemical species is taken into account assuming optically-thin gases. Our examination shows the capability of our numerical analysis for the flame structure prediction of the benchmark $\mathrm{CO} / \mathrm{H}_{2}$ flame. Indeed, the predicted distributions of temperature and chemical species concentrations within the flame are in good agreement with those of measurement. Then, we feed the bluff-body burner with different types of syngas fuels and report the emissions of greenhouse gases the gases exhausted from the combustor outlet. In this regard, we employ the syngas fuels produced from gasification process of biomass, wood waste, and turkey feathers to feed the required fuels of burner. Finally, we change the concentration of the inert $\mathrm{N}_{2}$ gas in the oxidizer to investigate the effects of oxidizer dilution on the resulting pollutant emissions from the aforementioned syngasfuel-based flames. Our investigation indicates different values of greenhouse gas concentrations at the combustor outlet for these syngas fuels under the imposed oxidizer dilutions.

\section{The Governing Equations}

In the cylindrical coordinates, the conservation laws for mass, $r$ - and $z$-momentums are given by

$$
\begin{gathered}
\nabla \cdot(\rho \mathbf{V})+\rho \frac{u}{r}=0 \\
\nabla \cdot(\rho \mathbf{V} u)=-\frac{\partial p}{\partial r}+\nabla \cdot\left(\mu_{e} \nabla u\right)+\mu_{e} \frac{1}{r} \frac{\partial u}{\partial r}-\mu_{e} \frac{u}{r^{2}} \\
\nabla \cdot(\rho \mathbf{V} v)=-\frac{\partial p}{\partial z}+\nabla \cdot\left(\mu_{e} \nabla v\right)+\mu_{e} \frac{1}{r} \frac{\partial v}{\partial r}+B_{z}
\end{gathered}
$$

where $\mu_{e}=\mu_{l}+\mu_{t}$ and $B_{z}=-\rho g$. The transport equations for turbulence quantities are given by 


$$
\begin{gathered}
\nabla \cdot(\rho \mathbf{V} \kappa)=\nabla \cdot\left(\frac{\mu_{e}}{\sigma_{\kappa}} \nabla \kappa\right)+\frac{\mu_{e}}{\sigma_{\kappa}} \frac{1}{r} \frac{\partial \kappa}{\partial r}+G_{\kappa}-\rho \varepsilon \\
\nabla \cdot(\rho \mathbf{V} \varepsilon)=\nabla \cdot\left(\frac{\mu_{e}}{\sigma_{\varepsilon}} \nabla \varepsilon\right)+\frac{\mu_{e}}{\sigma_{\varepsilon}} \frac{1}{r} \frac{\partial \varepsilon}{\partial r}+\frac{\varepsilon}{\kappa}\left(c_{1} G_{\kappa}-c_{2} \rho \varepsilon\right)
\end{gathered}
$$

where $G_{\kappa}=\mu_{e}\left\{2\left[(\partial v / \partial z)^{2}+(\partial u / \partial r)^{2}+(u / r)^{2}\right]+[(\partial v / \partial r)+(\partial u / \partial z)]^{2}\right\}$ and $\mu_{i}=c_{d} \rho \kappa^{2} / \varepsilon$. The constants of turbulence model are modified according to round jet corrections [11]. For regions near the solid walls, wall functions are used due to dominant viscous effects.

For combustion modelling, we use the steady laminar flamelet approach [12-19] in which the laminar flamelets are pre-computed via the detailed kinetic scheme of Qin [20]. The transport equations for the first two moment of mixture fractions are given by

$$
\begin{gathered}
\nabla \cdot(\rho \mathbf{V} f)=\nabla \cdot\left(\frac{\mu_{e}}{\sigma_{f}} \nabla f\right)+\frac{\mu_{e}}{\sigma_{f}} \frac{1}{r} \frac{\partial f}{\partial r} \\
\nabla \cdot\left(\rho \mathbf{V} f^{\prime \prime 2}\right)=\nabla \cdot\left(\frac{\mu_{e}}{\sigma_{f}} \nabla f^{\prime \prime 2}\right)+\frac{\mu_{e}}{\sigma_{f}} \frac{1}{r} \frac{\partial f^{\prime \prime 2}}{\partial r}+c_{g} \mu_{e}(\nabla f)^{2}-\rho c_{\chi} \frac{\varepsilon}{\kappa} f^{\prime \prime 2}
\end{gathered}
$$

The turbulence-chemistry interaction is regarded using the presumed-shape functions PDFs. The results from the precomputed laminar flamelets and turbulent statistics are tabulated as a lookup table. The data of this lookup table provide all thermo-chemical quantities of the solution domain during the numerical solution [21].

Assuming a unit Lewis number, the transport equation for the total enthalpy is given by

$$
\nabla \cdot(\rho \mathbf{V} h)=\nabla \cdot\left(\frac{\mu_{e}}{\sigma_{h}} \nabla h\right)+\frac{\mu_{e}}{\sigma_{h}} \frac{1}{r} \frac{\partial h}{\partial r}+q_{r a d}
$$

Thermal radiation of gaseous mixture is calculated assuming an optically thin flame. Eventually, the mixture density is obtained from the equation of state as $p=\rho R T \sum_{m=1}^{n} Y_{m} / W_{m}$.

\section{Computational Method}

The authors developed a hybrid FVE-PIS code [22-30] to use the advantages of both the cell-centred finite-volume FV method and the finite-element FE features. The solution domain is broken into a large number of quadrilateral elements and then each element is divided into four sub-quadrilaterals. All unknown variables are calculated at elements nodes, located at the element vertices. Assembling the four sub-quadrilaterals around a node, the finite volume cells are constructed in which the conservations laws are applied [22-30]. Discretizing the governing equations, we obtain a few systems of linear algebraic equations, i.e. eight equations corresponding to eight unknowns. The element stiffness matrices are derived and assembled properly to construct two sub-global stiffness matrices, corresponding to the fluid dynamics and thermo-chemistry parameters. They are solved in two stages within each iteration using the implicit and semi-implicit approaches.

\section{The Benchmark Test Case and Validation}

As elaborated before, a syngas turbulent non-premixed flame stabilized on an axisymmetric bluff-body burner is adopted as the benchmark problem. We compare our results against the experimental data to validate our numerical solutions. We implement the experimental conditions of Dally et al. [31] in our calculations. Because of the symmetry of problem, we consider a rectangular solution domain applying the symmetry boundary conditions at the centre line. The computational domain has $0.1 \mathrm{~m} \times 0.7 \mathrm{~m}$ dimensions. The burner has a bluff-body inside with diameter of $50 \mathrm{~mm}$. The fuel nozzle diameter is $3.6 \mathrm{~mm}$. The fuel consists of $33.3 \% \mathrm{CO}$ and $66.6 \% \mathrm{H}_{2}$ (by volume) and the oxidizer (dry air) consists of 
$23.3 \%$ oxygen and $76.7 \%$ nitrogen (by mass). The fuel nozzle injects the syngas at a speed of $134 \mathrm{~m} / \mathrm{s}$ into the combustor. The oxidizer, i.e. co-flow air stream, enters the combustor at a speed of $40 \mathrm{~m} / \mathrm{s}$. The initial temperatures of fuel and oxidizer are $298 \mathrm{~K}$ and $300 \mathrm{~K}$, respectively.

To compare the predicted flame structure with those of experiment, we present the distributions of mixture fraction, temperature, $\mathrm{OH}$ mass fraction, and root mean square RMS of mixture fraction in the flame. Figure 1 shows the distributions of these quantities at $\mathrm{z}=13,30,45,90,200$, and $400 \mathrm{~mm}$ in the flame. The distributions at these six sections are shown using circular symbols with different colours. As shown, the black, red, orange, green, blue, and pink colours are used to illustrate the distributions at $\mathrm{z}=13,30,45,90,200$, and $400 \mathrm{~mm}$, respectively. The distributions are compared to the measured data [31]. However, the distributions are not reported for the temperature and $\mathrm{OH}$ mass fraction at $\mathrm{z}=200$ and $400 \mathrm{~mm}$. It is because Dally et al. [31] did not report them at those sections. The comparison shows that there are good agreements between the obtained results and the experimental data. Of course, there are some discrepancies between them, which can be attributed to the defects of utilized turbulence and radiation models in our simulation. Unfortunately, the experiment is not described in detail by Ref. [31]. For example, they do not describe the exact inlet boundary conditions for the burner, e.g., the values for turbulence intensities, velocity profiles. Figure 1 reveals that the current numerical simulation can predict the structure of this flame suitably.
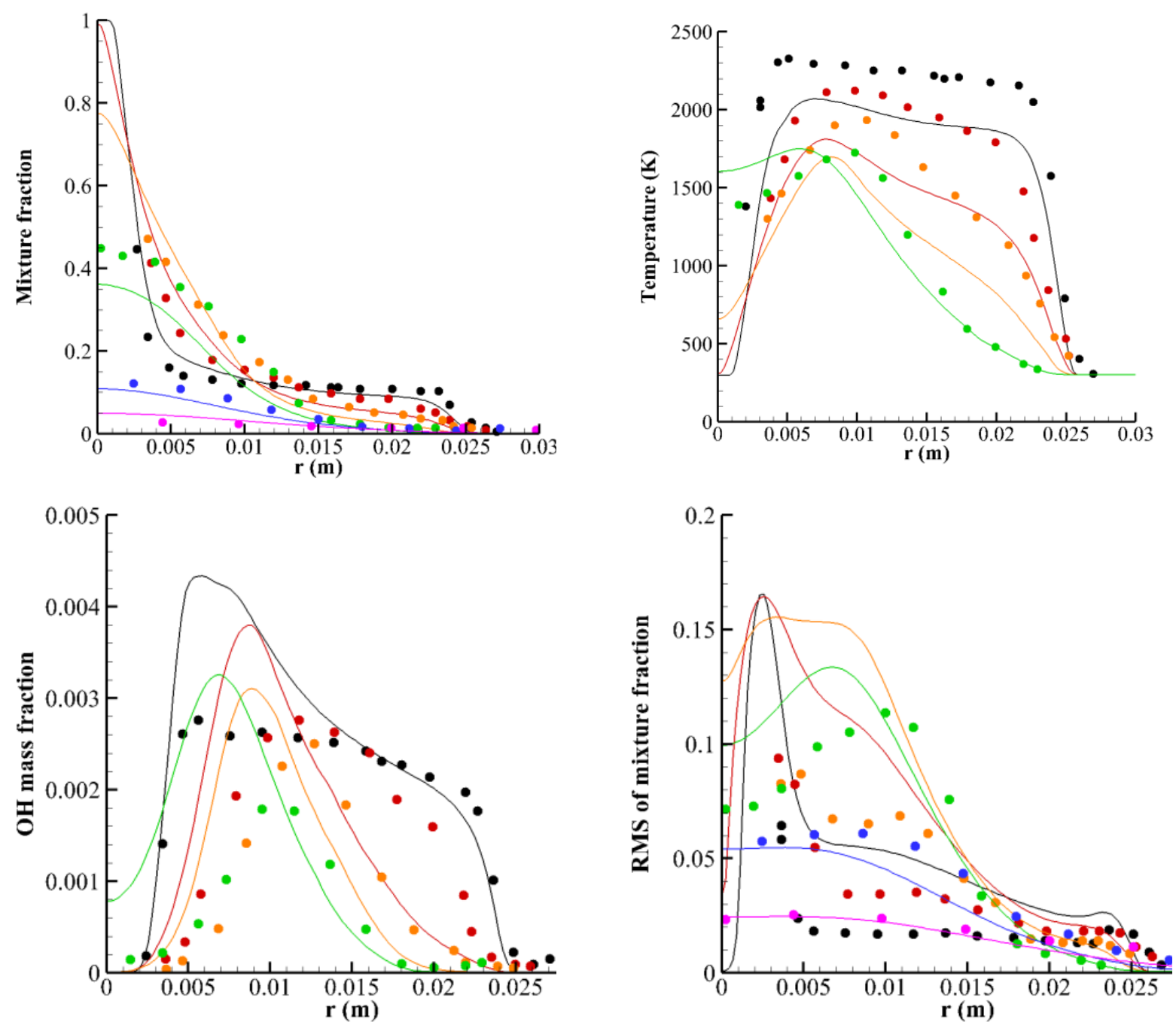

Fig. 1: The predicted flame structure (solid lines) for the benchmark test case and comparison with the experimental data [31] (symbols); where the black, red, orange, green, blue, and pink colours refer to the parameter distributions at $z=13,30,45,90,200$, and $400 \mathrm{~mm}$ sections, respectively. 


\section{The Greenhouse Gases Emission from Different Syngas Fuels under Different Oxidizer Dilution Feed.}

Now, we would like to extend the scope of current study by simulating different types of syngas fuels at different feeding conditions. In this regard, the bluff-body burner is fed with five different syngas fuels, i.e. syngas 1 , syngas 2 , syngas 3 , syngas 4 , and syngas 5 . These syngas fuels have different chemical compositions. They are produced from burning different waste resources. The fuel syngas 1 is the same fuel used in the benchmark test case. The syngas 2 is produced from biomass wastes. The syngas 3 and syngas 4 are produced from wood waste. The syngas 5 is produced from turkey feathers (wastes). Table 1 shows the approximate chemical compositions of these different syngas fuels.

Table 1. The chemical composition details of different syngas fuels studied in this work.

\begin{tabular}{|c|c|c|c|c|c|}
\hline & syngas 1 & syngas 2 & syngas 3 & syngas 4 & syngas 5 \\
\hline & (by volume) & (by volume) & (by mass) & (by mass) & (by volume) \\
\hline $\mathrm{CO}$ & 33.33 & 24 & 31.9 & 29.5 & 20 \\
\hline $\mathrm{H}_{2}$ & 66.66 & 18 & 0.6 & 0.5 & 8 \\
\hline $\mathrm{N}_{2}$ & - & 48.6 & 56.2 & 53.6 & 55 \\
\hline $\mathrm{H}_{2} \mathrm{O}$ & - & 6 & 1.8 & 2.7 & - \\
\hline $\mathrm{CH}_{4}$ & - & 3 & 1 & 2 & 5 \\
\hline $\mathrm{O}_{2}$ & - & 0.4 & - & 2.3 & 4 \\
\hline $\mathrm{CO}_{2}$ & - & - & 8.5 & 8.8 & - \\
\hline $\mathrm{C}_{3} \mathrm{H}_{8}$ & - & - & - & 0.5 & - \\
\hline $\mathrm{C}_{2} \mathrm{H}_{6}$ & - & - & - & 0.1 & 4 \\
\hline $\mathrm{CH}_{2}$ & - & - & - & - & 4 \\
\hline $\mathrm{C}_{2} \mathrm{H}_{2}$ & - & - & - & - & 5 \\
\hline
\end{tabular}

As mentioned before, different conditions of oxidizer dilution are simulated to elaborate its effects on the greenhouse gases emission from the aforementioned syngas fuels. In this regard, the oxidizer is diluted via feeding different concentration of extra nitrogen. In fact, the mass fraction of $\mathrm{N}_{2}$ in the oxidizer varies from 0 (oxy-fuel burner) to $77 \%$ (dry air). This trend would show the effects of oxidizer dilution via the inert gas $\mathrm{N}_{2}$ on the pollutant's concentrations and their emissions at the combustor outlet.

Figure 2 shows the average (mass-weighted) values of pollutant concentrations (mass fractions of methane, water vapour, carbon dioxide, and carbon monoxide) at the combustor outlet burning the aforementioned syngas fuels and the described oxidizer dilutions. Figure 2 different syngas fuels using different colours. To dilute the oxidizer with inert gas nitrogen, we impose different mass fraction magnitudes. As seen, we have diluted the oxidizer with $\mathrm{N}_{2}$ gas in a manner to reach suitable values of nitrogen mass fraction in the oxidizer mixture, i.e., 0, 25, 50, and 77 percentages. As is seen in this figure, the aforementioned oxidizer dilutions show different trends for different syngas fuel amounts in terms of methane concentration value within the exhaust gases. Indeed, the oxidizer dilution would reduce the methane concentration in fuel syngas 1, but it would increase the methane mass fraction from the fuel syngas 3 at the combustor outlet. The methane concentration in the exhaust gases would slightly change the fuel syngas 5 if the oxidizer is diluted by feeding suitable amount of nitrogen gas.

Figure 2 also shows that the concentrations of $\mathrm{H}_{2} \mathrm{O}$ and $\mathrm{CO}_{2}$ at the combustor outlet would not change for any of these syngas fuels under any of the oxidizer dilution values mentioned above. Finally, Figure 2 also shows that the CO concentration at the combustor outlet decreases for all of these syngas fuels if the oxidizer is diluted using the $\mathrm{N}_{2}$ gas. 

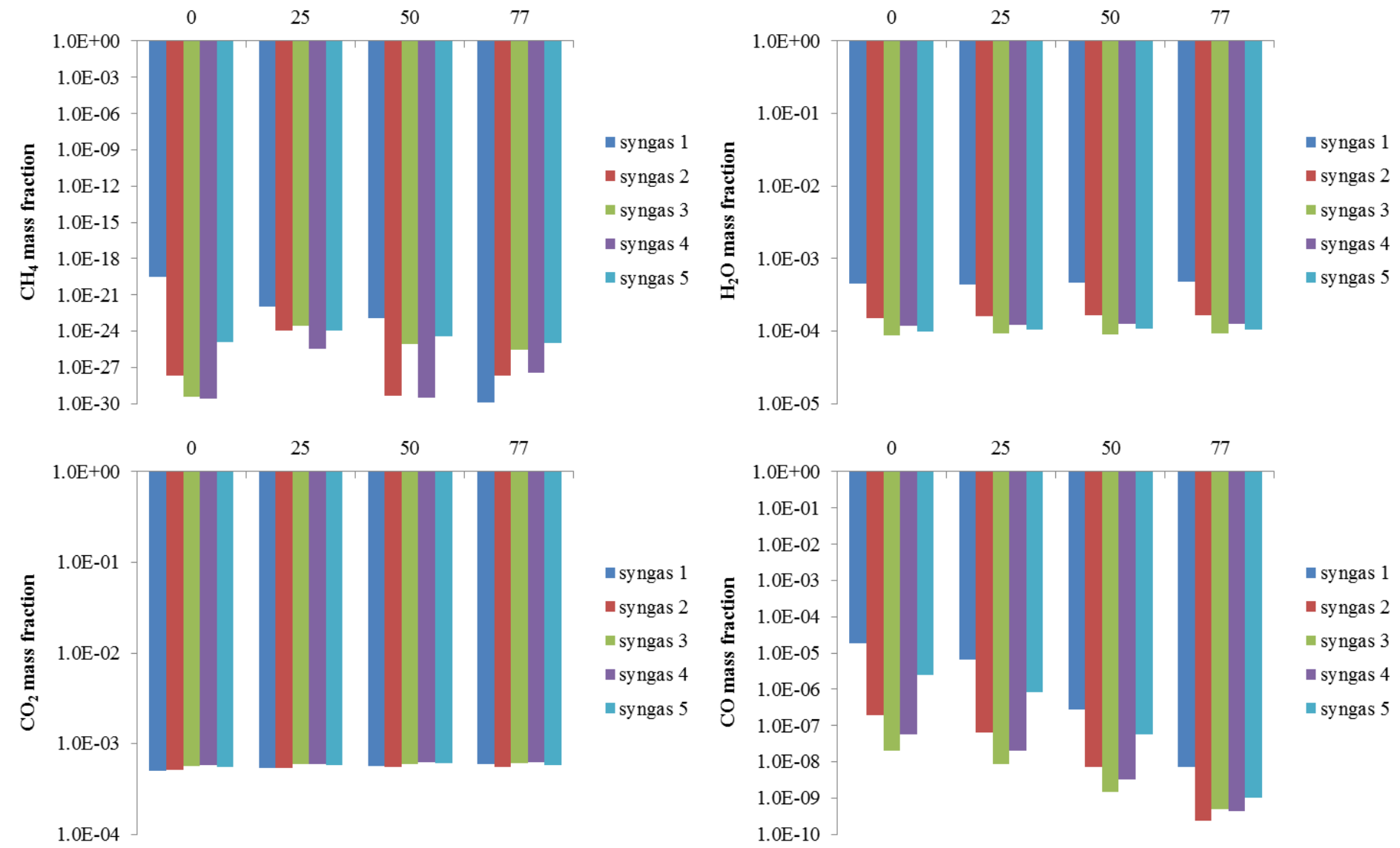

Fig. 2: The average (mass-weighted) values of species concentrations (mass fractions) at the combustor outlet for different types of syngas fuels considering different oxidizer dilution considerations, i.e., $0,25,50$, and $77 \%$ of nitrogen gas.

\section{Conclusion}

Different syngas turbulent non-premixed flames stabilized on an axisymmetric bluff-body were analysed numerically in this work. To do so, we used the detailed kinetic scheme of Qin, steady laminar flamelet approach, and the two-equation standard $\kappa-\varepsilon$ turbulence model to obtain the results. We utilized the finite-volume method to solve the aforementioned benchmark problem and examine the current numerical solutions. First, we examined the reliability of our method in predicting the flame structure of a benchmark $\mathrm{H}_{2} / \mathrm{CO}$ flame supported by the experimental data. Next, we fed the burner with different types of syngas fuels produced from biomass, wood waste, and turkey feathers. We reported the greenhouse gas emissions produced by burning these fuels. Finally, we changed the mass fraction of nitrogen in the oxidizer to investigate the effects of oxidizer dilution via the inert gas $\mathrm{N}_{2}$. In fact, we studied the effects on the emission of greenhouse gases at the combustor outlet. Our findings revealed that the oxidizer dilution via feeding the inert nitrogen gas would severely decrease the $\mathrm{CO}$ emission of these syngas fuels at the outlet. It was shown that the oxidizer dilution would slightly change the emissions of $\mathrm{CO}_{2}$ and water vapour from these syngas fuels at the combustor outlet.

\section{Acknowledgements}

The authors gratefully acknowledge funding from the Deputy of Research and Technology in Sharif University of Technology. 


\section{References}

[1] I. Wender, "Reactions of Synthesis Gas," Fuel Processing Technology, vol. 48, no. 3, pp. 189-297, 1996.

[2] S. H. Lee, K. B. Choi, J. G. Lee, and J. H. Kim, "Gasification Characteristics of Combustible Wastes in a 5 Ton/Day Fixed Bed Gasifier," Korean Journal of Chemical Engineering, vol. 23, no. 4, pp. 576-580, 2006.

[3] M. Dudynski, K. Kwiatkowski, and K. Bajer, "From Feathers to Syngas - Technologies and Devices," Waste Management, vol. 32, no. 4, pp. 685-691, 2012.

[4] K. Kwiatkowski, M. Dudy'nski, and K. Bajer, "Combustion of Low-Calorific Waste Biomass Syngas," Flow, Turbulence and Combustion, vol. 91, pp. 749-772, 2013.

[5] S. G. Davis, A. V. Joshi, H. Wang, and F. Egolfopoulos, "An Optimized Kinetic Model of $\mathrm{H}_{2} / \mathrm{CO}$ Combustion," Proceedings of the Combustion Institute, vol. 30, no. 1, pp. 1283-1292, 2005.

[6] I. G. Zsély, J. Zádor, and T. Turányi, "Uncertainty Analysis of Updated Hydrogen and Carbon Monoxide Oxidation Mechanisms," Proceedings of the Combustion Institute, vol. 30, no. 1, pp. 1273-1281, 2005.

[7] J. Natarajan, T. Lieuwen, and J. Seitzman, "Laminar Flame Speeds of $\mathrm{H}_{2} / \mathrm{CO}$ Mixtures: Effect of $\mathrm{CO}_{2}$ Dilution, Preheat Temperature, and Pressure," Combustion and Flame, vol. 151, no. 1-2, pp. 104-119, 2007.

[8] H. Sun, S. I. Yang, G. Jomaas, and C. K. Law, "High-Pressure Laminar Flame Speeds and Kinetic Modeling of Carbon Monoxide/Hydrogen Combustion," Proceedings of the Combustion Institute, vol. 31, no. 1, pp. 439-446, 2007.

[9] T. C. Williams, C. R. Shaddix, and R. W. Schefer, "Effect of Syngas Composition and $\mathrm{CO}_{2}$-Diluted Oxygen on Performance of a Premixed Swirl-Stabilized Combustor," Combustion Science and Technology, vol. 180, no. 1, pp. 64-88, 2007.

[10] F. L. Dryer and M. Chaos, "Ignition of Syngas/Air and Hydrogen/Air Mixtures at Low Temperatures and High Pressures: Experimental Data Interpretation and Kinetic Modeling Implications," Combustion and Flame, vol. 152, no. 1-2, pp. 293-299, 2008.

[11] J. H. Kent and D. Honnery, "Soot and Mixture Fraction in Turbulent Diffusion Flames," Combustion Science and Technology, vol. 54, no. 1-6, pp. 383-397, 1987.

[12] N. Peters, "Laminar Diffusion Flamelet Models in Non-Premixed Turbulent Combustion," Progress in Energy and Combustion Science, vol. 10, no. 3, pp. 319-339, 1984.

[13] D. C. Haworth, M. C. Drake, and R. J. Blint, "Stretched Laminar Flamelet Modeling of a Turbulent Jet Diffusion Flame," Combustion Science and Technology, vol. 60, no. 4-6, pp. 287-318, 1988.

[14] M. Oevermann, "Numerical Investigation of Turbulent Hydrogen Combustion in a Scramjet Using Flamelet Modeling," Aerospace Science and Technology, vol. 4, no. 7, pp. 463-480, 2000.

[15] M. Hossain, J. C. Jones, and W. Malalasekera, "Modelling of a Bluff-Body Nonpremixed Flame Using a Coupled Radiation/Flamelet Combustion Model," Flow, Turbulence and Combustion, vol. 67, pp. 217-234, 2001.

[16] S. Kang and Y. Kim, "Parallel Unstructured-Grid Finite-Volume Method for Turbulent Nonpremixed Flames Using the Flamelet Model," Numerical Heat Transfer, Part B: Fundamentals: An International Journal of Computation and Methodology, vol. 43, no. 6, pp. 525-547, 2003.

[17] F. Hunger, B. Stelzner, D. Trimis, and C. Hasse, "Flamelet-Modeling of Inverse Rich Diffusion Flames," Flow, Turbulence and Combustion, vol. 90, no. 4, pp. 833-857, 2013.

[18] R. Prieler, M. Demuth, D. Spoljaric, and C. Hochenauer, "Evaluation of a Steady Flamelet Approach for Use in Oxy-Fuel Combustion," Fuel, vol. 118, pp. 55-68, 2014.

[19] R. Prieler, M. Demuth, D. Spoljaric, and C. Hochenauer, "Numerical Investigation of the Steady Flamelet Approach under Different Combustion Environments," Fuel, vol. 140, pp. 731-743, 2015.

[20] Z. Qin, V. V. Lissianski, H. Yang, W. C. Gardiner, S. G. Davis, and H. Wang, "Combustion Chemistry of Propane: A Case Study of Detailed Reaction Mechanism Optimization," Proceedings of the Combustion Institute, vol. 28, pp. 1663-1669, 2000.

[21] E. Sozer et al., "Turbulence-Chemistry Interaction and Heat Transfer Modeling of H2/O2 Gaseous Injector Flows," in 48th AIAA Aerospace Sciences Meeting Including the New Horizons Forum and Aerospace Exposition, Orlando, Florida, 2010, pp. AIAA 2010-1525.

[22] M. Darbandi, M. Ghafourizadeh, and G. E. Schneider, "A Novel FEV Formulation to Solve Laminar Diffusive Flame in the Cylindrical Coordinates," in $46^{\text {th }}$ AIAA Aerospace Sciences Meeting and Exhibit, Reno, Nevada, 2008, pp. AIAA 2008-1257: American Institute of Aeronautics and Astronautics, 2008. 
[23] M. Darbandi, M. Ghafourizadeh, and G. E. Schneider, "Numerical Calculation of Turbulent Reacting Flow in a Model Gas-Turbine Combustor," in $41^{s t}$ AIAA Thermophysics Conference, San Antonio, Texas, 2009, pp. AIAA 2009-3926, American Institute of Aeronautics and Astronautics, 2009.

[24] M. Darbandi, M. Ghafourizadeh, and G. E. Schneider, "Numerical Simulation of Turbulent Reacting Flow in a Combustion Chamber Using Detailed Chemical Kinetics," in 51 AIAA Aerospace Sciences Meeting including the New Horizons Forum and Aerospace Exposition, Grapevine (Dallas/Ft. Worth Region), Texas, 2013, pp. AIAA 2013-0710: American Institute of Aeronautics and Astronautics, 2013.

[25] M. Darbandi and M. Ghafourizadeh, "Extending a Hybrid Finite-Volume-Element Method to Solve Laminar Diffusive Flame," (in English), Numerical Heat Transfer, Part B: Fundamentals: An International Journal of Computation and Methodology, vol. 66, no. 2, pp. 181-210, 2014.

[26] M. Darbandi, M. Ghafourizadeh, and G. E. Schneider, "Finite Element Volume Analysis of Propane Preheated Air Flame Passing through a Minichannel," in ASME $201412^{\text {th }}$ International Conference on Nanochannels, Microchannels, and Minichannels, Chicago, Illinois, USA, 2014, pp. ICNMM2014-21832, V001T13A002: American Society of Mechanical Engineers, 2014.

[27] M. Darbandi and M. Ghafourizadeh, "Solving Turbulent Diffusion Flame in Cylindrical Frame Applying an Improved Advective Kinetics Scheme," (in English), Theoretical and Computational Fluid Dynamics vol. 29, no. 56, pp. 413-431, 2015.

[28] M. Darbandi, M. Ghafourizadeh, and G. E. Schneider, "Datailed-Chemistry Modeling of a Bluff-Body Stabilized Methanol/Air Turbulent Nonpremixed Flame Using Finite-Element-Volume Method," in $2^{\text {nd }}$ International Conference on Fluid Flow, Heat and Mass Transfer, Ottawa, Ontario, Canada, 2015, pp. 154 (1-8), 2015.

[29] M. Darbandi and M. Ghafourizadeh, "A New Bi-Implicit Finite Volume Element Method for Coupled Systems of Turbulent Flow and Aerosol-Combustion Dynamics," Journal of Coupled Systems and Multiscale Dynamics, vol. 4, no. 1, pp. 43-59, 2016.

[30] M. Ghafourizadeh, M. Darbandi, and G. E. Schneider, "Using Hydrogen Influences to Control the Greenhouse Gas Emissions from Methane-Hydrogen Turbulent Flame," in $3^{\text {rd }}$ International Conference on Fluid Flow, Heat and Mass Transfer (FFHMT'16), pp. 166-1-8, 2016.

[31] B. B. Dally, A. R. Masri, R. S. Barlow, and G. J. Fiechtner, "Instantaneous and Mean Compositional Structure of Bluff-Body Stabilized Nonpremixed Flames," Combustion and Flame, vol. 114, pp. 119 -148, 1998. 